\title{
Brincadeira e aprendizagem do uso de ferramentas em macacos- prego (Cebus apella)
}

\author{
Briseida Dôgo de Resende \\ Eduardo B. Ottoni \\ Universidade de São Paulo
}

\begin{abstract}
Resumo
Nossa pesquisa tem como objetivo estudar o desenvolvimento dos infantes e juvenis de um grupo de macacos-prego (Cebus apella) em condição de semiliberdade, com ênfase nos comportamentos manipulativos. No presente estudo, relacionamos o aparecimento do uso de instrumentos para quebra de cocos com a brincadeira social e com a brincadeira com objetos. A brincadeira social ocorreu predominantemente em infantes e juvenis. A brincadeira com objetos, muitas vezes indistinguível das atividades exploratórias, aumentou durante o primeiro ano de vida. A manipulação exploratória de pedras constitui uma oportunidade importante para a aprendizagem individual, por tentativa-e-erro, do uso de instrumentos para quebrar cocos, que surge entre o segundo e o terceiro anos de vida. A brincadeira social parece facilitar a tolerância entre os sujeitos, o que favoreceria a aprendizagem por observação dos episódios de quebra.
\end{abstract}

Palavras-chave: Brincadeira, Macaco-prego, Uso de ferramentas, Aprendizagem.

\begin{abstract}
Play and tool use learning in tufted capuchin monkeys (Cebus apella)

The aim of our research is the study of the development of young tufted capuchin monkeys (Cebus apella) from a semi-free group, with an emphasis in manipulative behaviors. In the present study, we discuss the relations between the appearance of tool-use in nutcracking and social and object play. Social play occured mainly among infant and juvenile subjects. Object play is often indistinct from exploratory activities and increased during the first year of life. The appearance of the use of tools for cracking nuts, between the second and the third year, is related to exploratory manipulation because of its importance for trial-and-error learning. Social play may facilitate tolerance among subjects and hence favour the observational learning of nutcracking.
\end{abstract}

Key words: Play, Tufted capuchin monkeys, Tool use, Learning.

A

brincadeira é um comportamento facilmente detectado, mas de difícil definição (Beckoff \& Byers, 1998; Walters, 1987). Segundo Walters (1987), ela incorpora muitos componentes físicos dos padrões comportamentais dos adultos, como aqueles usados durante as agressões (mas sem suas conseqüências imediatas), sendo exagerada, repetitiva e variada. Para Rasa (1984), a brincadeira é provavelmente um dos complexos comportamentais mais enigmáticos, principalmente porque não parece ter nenhuma importância biológica evidente, o que se deve à falta de um ato consumatório.

Quase todos os mamíferos e muitas espécies de aves brincam. Burghart (1998) inclui os répteis entre os animais que podem brincar e acrescenta que quanto maior a complexidade cerebral, mais elaboradas são as formas de brincadeira.

Há três tipos de brincadeira comumente aceitos: brincadeira com objetos, na qual o sujeito manipula um objeto de uma maneira repetitiva; brincadeira locomotora (ou solitária), em que o sujeito pula e corre sozinho; e brincadeira social, que envolve mais de um indivíduo e consiste basicamente em pega-pega ou luta (Burghart, 1998; Walters, 1987).

Segundo Beckoff e Allen (1998), tentativas de definir funcionalmente o comportamento "brincadeira" enfrentam o problema de sua função não ser óbvia no momento em que é praticado, ou mais tarde na vida do sujeito. Walters 
(1987) aponta a existência de várias hipóteses a respeito da função da brincadeira, a maioria delas propondo que ela facilita o desenvolvimento social (o que se refere apenas à brincadeira social). Segundo Lewis (2000), como o comportamento de brincadeira é particularmente associado a jovens, parece provável que ocorra neste período sensível do desenvolvimento para maximizar o potencial de aprendizagem.

A brincadeira (de qualquer das modalidades mencionadas) também pode funcionar como um treinamento de habilidades motoras que não podem ser praticadas no seu contexto apropriado (como interações agonísticas ou fuga de predadores, por exemplo). Fagen (1981) propõe que a brincadeira poderia funcionar como um treinamento físico, pois as atividades repetitivas usadas neste contexto modificariam a fisiologia do indivíduo, tornandoo mais apto a sobreviver no ambiente particular em que nasceu. No entanto, Beckoff e Allen (1998) alertam que é complicado provar a consistência das hipóteses, já que as vantagens reprodutivas da brincadeira podem ocorrer tão mais tarde na vida dos indivíduos envolvidos que seria difícil coletar os dados que apoiassem a afirmação de que há um aumento na aptidão (fitness) de indivíduos que brincam mais comparados àqueles que brincam menos. Mendonza-Granados e Sommer (1995), que estudaram a brincadeira (social, solitária e com objetos) de chimpanzés em cativeiro, enfatizam que a hipótese de custos imediatos para benefícios futuros está longe de ter sido provada e afirmam que a maior parte dos atributos da brincadeira descritos em seu trabalho pode ser entendida como provedora de benefícios imediatos aos jovens através da facilitação do seu desenvolvimento físico e das interações com os parceiros. Sommer e Mendonza-Granados (1995), comparando um grupo de langures selvagens (Presbytis entellus) que vivia em uma área rica com outro grupo que habitava uma área mais árida (menos água e fontes alimentares), notaram que no ambiente mais rico havia mais brincadeira (social e locomotora) do que no mais árido, mas ressaltam que sujeitos que brincam pouco, ou não brincam, podem se desenvolver sem problemas aparentes. Chalmers e LockeHaydon (1984), que correlacionaram o desenvolvimento de habilidades motoras com a brincadeira social em sagüis (Callithrix jacchus jacchus), sugerem que há custos e benefícios imediatos na brincadeira.

\section{Brincadeira social}

Apesar da brincadeira em primatas ser estruturalmente parecida entre as espécies, a identidade dos parceiros pode variar em decorrência das variações na estrutura social (Walters, 1987). Quando possível, primatas jovens tendem a brincar com sujeitos de tamanho e força semelhantes aos seus. Mendonza-Granados e Sommer (1995), estu- dando chimpanzés, verificaram que parceiros de idade semelhante eram preferidos e que os parceiros mais velhos iniciavam as brincadeiras com mais freqüência. No caso de espécies em que há formação de linhagens matriarcais, sugeriu-se que as relações de dominância das fêmeas adultas afetam a escolha de parceiros de brincadeiras por juvenis: fêmeas poderiam usar a brincadeira para desenvolver laços com indivíduos de melhor posição hierárquica (Cheney, 1978).

Biben (1998) afirma que micos-de-cheiro (Saimiri sciureus) preferem brincar com quem podem dominar e que, numa brincadeira de luta, vence mais vezes quem é dominante fora da brincadeira, mas a extensão da diferença na relação de dominância é abrandada: o dominante pode, em alguns eventos, trocar de papel com o subordinado, o que é muito mais freqüente nas brincadeiras entre machos do que entre fêmeas. Talvez por isso, os machos brincam muito mais que as fêmeas nesta espécie. Em outras espécies, como babuínos (Papio hamadryas) e vervets (Cercopithecus aethiops), a taxa de brincadeira também é maior entre os machos (Walters, 1987). No grupo de chimpanzés de Mendonza-Granados e Sommer (1995), as fềmeas gastaram mais tempo em brincadeira solitária do que os machos, cujo registro de brincadeira social foi maior. Para estes autores, o fator que faz a diferença na quantidade de brincadeira é a possibilidade ou não de haver alianças entre indivíduos do mesmo sexo.

Quando há um desequilíbrio de forças entre os parceiros, é comum que o mais forte evite usar toda sua habilidade física (fenômeno conhecido por self-handcapping) e, assim, os mais fracos continuam interessados pela brincadeira (Biben, 1998; Pereira \& Preisser, 1998).

\section{Brincadeira com objetos}

A brincadeira com objetos permite que juvenis explorem novos estímulos, objetos, além de poder ser vista como um treino motor, com vários benefícios físiológicos (Hall, 1998). Bateson, Mendl e Feaver (1990) verificaram que a redução da disponibilidade de alimento para gatas durante o período de amamentação aumentava significativamente a brincadeira com objetos nos filhotes. Pellis (1991), ao registrar brincadeira em focas de cativeiro em diferentes horas do dia, notou que a brincadeira com objetos aumentava conforme se aproximava o horário da alimentação, enquanto a brincadeira social diminuía. Segundo o autor, à medida que os animais iam ficando com fome, eles dirigiam mais sua atenção a comportamentos "pseudo-alimentares", ou seja, aumentavam o tempo dedicado à brincadeira com objetos, e havia uma diminuição na tolerância para com as outras focas. 
A brincadeira com objetos se confunde com outras atividades exploratórias, sendo difícil separar padrões comportamentais lúdicos dos não-lúdicos (Rasa, 1984). Esse problema é amenizado no estudo de espécies que apresentam uma vocalização específica para o contexto de brincadeira, como é o caso dos mangustos estudados por Rasa. Para a autora, tal vocalização teria surgido num contexto social para sinalizar a intenção de brincadeira e teria se expandido para a brincadeira com objetos.

Schiller (1949/1978) ofereceu objetos a chimpanzés de cativeiro e depois submeteu-os a testes em que deveriam usar tais objetos para solucionar tarefas. Este autor concluiu que a presença da brincadeira era pré-requisito para a solução de determinados problemas e que a brincadeira é diferente do comportamento usado para conseguir comida: o sujeito aprende durante a brincadeira e depois aplica o que foi aprendido na solução de um dado problema.

Um caso interessante de manipulação inovadora de objetos, sem finalidade aparente, que se difundiu socialmente, é a manipulação de pedras por macacos japoneses (Macaca fuscata) do Parque Natural de Iwatayama, no Japão (Huffman, 1984). Este comportamento envolve coletar pedras, juntá-las numa pilha ou separar as pilhas; pegar pedras e soltá-las ou espalhá-las no chão; esfregar uma ou duas pedras entre as mãos; segurar uma pedra em cada mão e esfregá-las ou batê-las, e carregar pedras, mantendo-as em contato com o corpo. Apresentada inicialmente por uma fêmea de três anos, a manipulação de pedras espalhou-se para outros membros do grupo nos anos seguintes e ocorre preferencialmente nos períodos imediatamente após a alimentação. Segundo Huffman, esta maneira de manipular pedras deve ser relaxante e auto-recompensadora, trazendo benefícios que podem ser de natureza psicológica ou fisiológica (Huffman, 1996).

\section{Os macacos-prego (Cebus apella)}

Os macacos-prego vivem, na natureza, em grupos multi-machos e multi-fêmeas compostos por 8 a 14 indivíduos (Terborgh, 1983). São animais de cerca de $3 \mathrm{~kg}$ que se destacam por sua grande habilidade motora e cognitiva, pois são capazes de usar objetos como ferramentas espontaneamente, como, por exemplo, pedras para abrir cocos de jerivá (Syagrus romanzoffiana; Ottoni \& Mannu, 2001), ou de forma experimentalmente induzida, como palitos para pegar alimentos de um tubo (Visalberghi, Fragaszy \& Savage-Rumbaugh, 1995) ou para extrair melado através dos orifícios de uma caixa (Perondi, Izar \& Ottoni, 1995; Westergaard \& Fragaszy; 1987). Em ambiente natural, os machos migram para outros grupos ao atingirem a maturidade sexual. (Terborgh, 1983). Welker, Becker,
Höhmann \& Schäfer-Witt (1987), a partir do estudo das relações sociais em um grupo de cativeiro, afirmam que outros infantes nascidos no mesmo ano e juvenis um ano mais velhos são parceiros de brincadeira mais atraentes até do que os irmãos. Nenhuma das variedades de brincadeira foi estudada em profundidade em macacosprego.

\section{Objetivos}

Pretendemos neste trabalho realizar um estudo preliminar da brincadeira em macacos-prego, procurando discutir a importância da brincadeira social e com objetos para a aprendizagem do uso de ferramentas na quebra de cocos por um grupo estudado em situação de semiliberdade.

\section{Método}

\section{Sujeitos e local}

Os sujeitos estudados são membros de um grupo de macacos-prego pertencente ao Parque Ecológico do Tietê (PET). Vivem numa área de $180.000 \mathrm{~m}^{2}$ que contém três lagos, algumas construções pequenas, vegetação arbustiva, eucaliptos e árvores frutíferas como jabuticabeiras, bananeiras, limoeiros, goiabeiras e amoreiras. A área possui quatro espécies de palmeiras, incluindo o supracitado jerivá.

O grupo observado vive nesta área há, pelo menos, 10 anos. No período em que foi feita a coleta de dados, o grupo variou de 23 a 25 indivíduos, incluindo, ao final, oito machos adultos ou subadultos (dois castrados), quatro fêmeas adultas (houve óbito de uma fêmea em janeiro de 2001) e 12 infantes ou juvenis (entre zero e 5 anos), sendo cinco fêmeas e sete machos (houve óbito de um infante em julho de 2000). Foram considerados "infantes" os sujeitos de 0 a 1 ano, idade aproximada do desmame. Foram incluídos na categoria "juvenil 1" os sujeitos de 1 a 2 anos de idade e, na categoria "juvenil 2", os sujeitos entre 2 e 5 anos. Durante o período de coleta, passaram pela faixa-etária infante quatro machos, três fêmeas e um sujeito de sexo indeterminado; pela faixa-etária juvenil 1, três machos e uma fêmea e, por juvenil 2, três machos.

Os animais recebem uma provisão de frutas e verduras, além de se alimentarem de insetos, ovos e frutas encontrados em árvores, e de alpiste, milho e farelo oferecidos aos outros animais do PET. Como o objetivo deste estudo era analisar a ontogênese do comportamento de quebra de cocos, a coleta de dados concentrou-se nos sujeitos com idade entre 0 e 144 semanas (cerca de 2 anos e 9 meses), levando em consideração seus parceiros de brincadeira e suas idades. O limite de 144 semanas foi escolhido por ter sido verificado em estudos anteriores que dentro deste período inicia-se a quebra de cocos. 


\section{A quebra de cocos}

Para quebrar cocos, os animais utilizam uma superficie dura e razoavelmente plana sobre a qual ajeitam o fruto (a "bigorna"). A bigorna pode ser móvel ou não (uma pedra ou o próprio chão). Os animais golpeiam o coco sobre a bigorna com outra pedra (o "martelo") repetidas vezes até que a casca do fruto se rompa e, então, ingerem o endosperma. Quanto mais experiente for o indivíduo, menos batidas são necessárias para abrir o coco.

A aprendizagem da quebra de cocos é um processo gradual que pode ser dividido, para fins de descrição, em três etapas. Inicialmente, entre os indivíduos mais jovens, é possível notar um grande interesse pela investigação das pedras e dos cocos dos sítios; mais tarde, os animais, especialmente infantes e juvenis, podem tentar quebrar cocos utilizando ferramentas inadequadas (como um martelo muito pequeno, ou uma bigorna da qual o coco escorrega) ou, apesar de ajeitarem o coco adequadamente, podem bater o martelo diretamente contra a bigorna. A estas situações chamamos de "quebra inepta". Nestas primeiras etapas, que antecedem a das quebras bem sucedidas, só há reforço alimentar quando há restos de cocos nos sítios (o que ocorre com razoável freqüência).

\section{Procedimento}

A coleta de dados foi feita entre março de 2000 e abril de 2001. Utilizamos o método do animal focal (Altmann, 1974): para cada filhote com idade inferior a 144 semanas, foram feitas duas observações focais contínuas de 10 minutos de duração por semana (uma no período da manhã até $12 \mathrm{~h} 00$ - e outra no período da tarde - a partir de $12 \mathrm{~h} 01$; a divisão de períodos foi feita porque as atividades do grupo variam de acordo com a hora do dia). As observações focais foram gravadas em fita cassete e transcritas para computador com o auxílio do programa EthoLog 2.2 (Ottoni, 2000). O etograma utilizado consiste de 37 categorias distribuídas em três grupos: sociais (catação, brin- cadeira social, transporte de filhote); autodirigidas (autocatação, descanso e locomoção) e manipulativas (ingestão e manipulação e exploração de objetos, alimentos, pedras). A "brincadeira social", envolvendo dois ou mais indivíduos, consiste, na maior parte das vezes, em pega-pega e brincadeira de luta: os sujeitos podem tentar agarrar o(s) outro(s), pulando nos galhos, correndo ou rolando pelo chão ou outros substratos (troncos, telhados). A expressão facial de brincadeira (boca relaxada com dentes à mostra, pálpebras semi-cerradas) é constante nestes eventos. Como é muito difícil distinguir a brincadeira com objetos da manipulação em geral, optamos por trabalhar com o termo "manipulação exploratória", registrada quando o sujeito explora objetos (não incluídos os alimentos), podendo pegá-los, revirá-los, batê-los contra uma superfície ou contra outro objeto, introduzir dedos no objeto, jogá-lo para cima ou esfregá-lo contra uma superfície. O comportamento de quebra não foi registrado como manipulação exploratória, mas como "quebra" (proficiente ou inepta). No entanto, foi registrado como "manipulação exploratória" o comportamento de examinar as pedras dos sítios de quebra e batidas de pedra contra pedra quando a postura do animal não era a mesma utilizada durante a quebra.

O número de sujeitos com menos de 144 semanas no grupo variou de cinco a sete no período. Não há o mesmo número de observações focais por sujeito (Tabela 1) devido a nascimentos ou desaparecimentos no período e à dificuldade de coleta em determinados dias (grupo em local com visibilidade prejudicada).

Obtivemos um total de 613 observações focais de 10 minutos, o que equivale a aproximadamente 102 horas. Foi registrada a duração dos episódios de brincadeira social. A manipulação exploratória foi medida em termos de freqüência de episódios por hora de observação. Foram também feitos registros ad libitum de eventos de brincadeira social e de manipulação exploratória e registros de todas

Tabela 1. Número de observações focais $(10 \mathrm{~min})$ por sujeito. Macho: m; Fêmea: f; Indeterminado: $i$

\begin{tabular}{lll}
\hline Sujeitos & Data de nascimento & $\begin{array}{l}\text { Número de } \\
\text { observações focais }\end{array}$ \\
\hline Manoel (m) & $23 / 06 / 98$ & 110 \\
Darwin (m) & $22 / 05 / 99$ & 111 \\
Químico (m) & $30 / 05 / 99$ & 109 \\
Joana (f) & $22 / 10 / 99$ & 109 \\
André(i) & $30 / 11 / 99$ & $32^{\mathrm{a}}$ \\
Fractal (f) & $24 / 06 / 00$ & $81^{\mathrm{b}}$ \\
Ada (f) & $25 / 12 / 00$ & $32^{\mathrm{b}}$ \\
Janeiro (f) & $08 / 01 / 01$ & $30^{\mathrm{b}}$ \\
\hline a desaparecido no dia 10/07/2000 & \\
b nascimentos após o início da coleta
\end{tabular}


as ocorrências de quebra envolvendo todos os sujeitos do grupo, anotando-se os eventos em que houve observação da quebra por coespecíficos, com a eventual ingestão subseqüente de restos de endosperma.

\section{Resultados}

\section{Brincadeira social}

Os sujeitos passaram cerca de 166 minutos em brincadeira social ( 2 horas e 46 minutos), sendo que machos e fêmeas da mesma faixa etária tendem a investir uma quantidade de tempo semelhante nesta atividade. A brincadeira social tende a aumentar até o início do segundo ano de idade (Figura 1). Os sujeitos parecem preferir parceiros de brincadeira que estejam em faixa etária semelhante (como observado por Welker et al., 1987), mas estes dados (Figura 2) carecem de independência entre as faixas etárias, já que houve mudanças de faixa no período. Assim, além dos viéses decorrentes do pequeno tamanho da amostra, há ainda o efeito de relações estáveis entre díades particulares que se prolongam no tempo, contribuindo para as freqüências observadas em mais de uma faixa etária. Os parceiros adultos e sub-adultos indicados na Figura 2 eram, em sua quase totalidade, machos (4,34\% dos 139 minutos em que foi possível registrar os parceiros): as fêmeas adultas só foram vistas brincando quando seus filhotes estavam presentes e, mesmo neste contexto, este comportamento foi raro.

Registros ad libitum mostram que os juvenis fizeram várias tentativas de brincadeira dirigidas a quatis (Nasua nasua) adultos ou filhotes. Na maior parte dos eventos, os quatis mudavam de lugar, mas pudemos observar uma ocasião em que - quando os adultos de ambas as espécies estavam descansando - os quatis filhotes interagiram com os macacos juvenis numa brincadeira social interespecífica.

Os infantes e juvenis muitas vezes alternavam a brincadeira social com a manipulação exploratória: interrompiam brincadeiras turbulentas ou pega-pega e começavam a manipular pedras, gravetos ou outros objetos. Tais períodos de brincadeira ocorriam freqüentemente após o provisionamento diário, enquanto os adultos descansavam.

\section{Brincadeira com objetos: manipulação exploratória}

Os macacos-prego do PET manipulam uma grande variedade de objetos, tanto naturais quanto manufaturados - e a manipulação de pedras é parte importante desta atividade. Apenas um animal com mais de um ano de idade não foi observado nesta atividade (embora manipulasse outros objetos e mostrasse interesse pela manipulação de pedras por outros indivíduos). A exploração de pedras envolve comportamentos como jogar pedras para cima, esfregar uma pedra entre as mãos ou segurar uma pedra em cada mão e batê-las uma contra a outra.

Nos sujeitos de 0 a 144 semanas, a freqüência de manipulação exploratória de objetos tende a crescer durante o primeiro ano de idade, mas foi observada uma queda do início para a metade do primeiro ano, para a única fêmea nesta faixa-etária, e da metade do primeiro ano para o início do segundo para os dois machos (Figu-

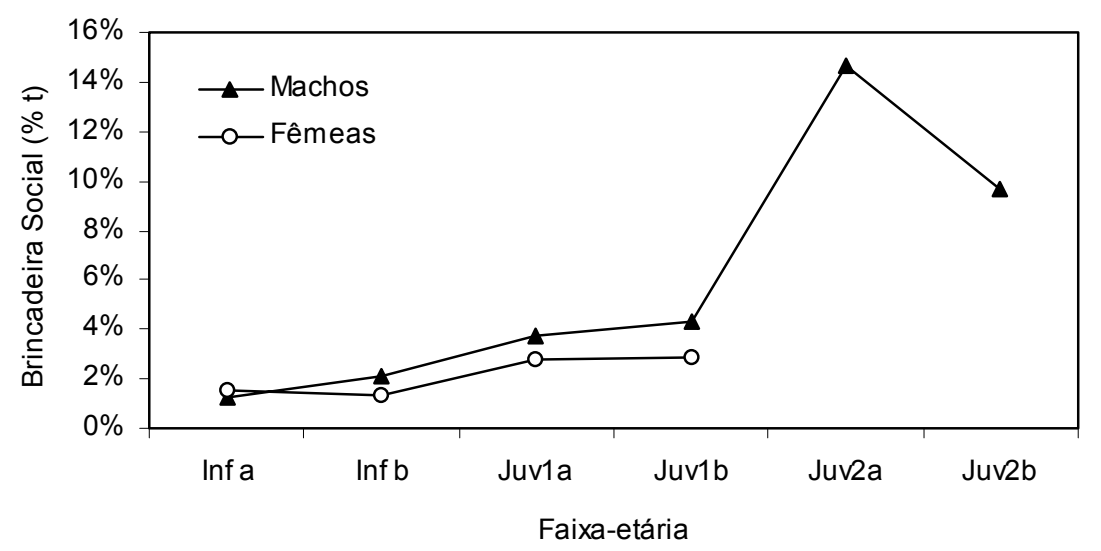

Figura 1. Porcentagem de tempo de brincadeira social apresentada pelos sujeitos de 0 a 144 semanas. As categorias infante, juvenil 1 e juvenil 2 foram divididas em infante a ( 0 a 24 semanas), infante b (25 a 48 semanas), juvenil 1a (49 a 72 semanas), juvenil 1b (73 a 96 semanas), juvenil 2a (97 a 120 semanas) e juvenil 2b (121 a 144 semanas). Os dados referentes a André não foram computados para esta análise, por ter sido possível identificar o sexo. 


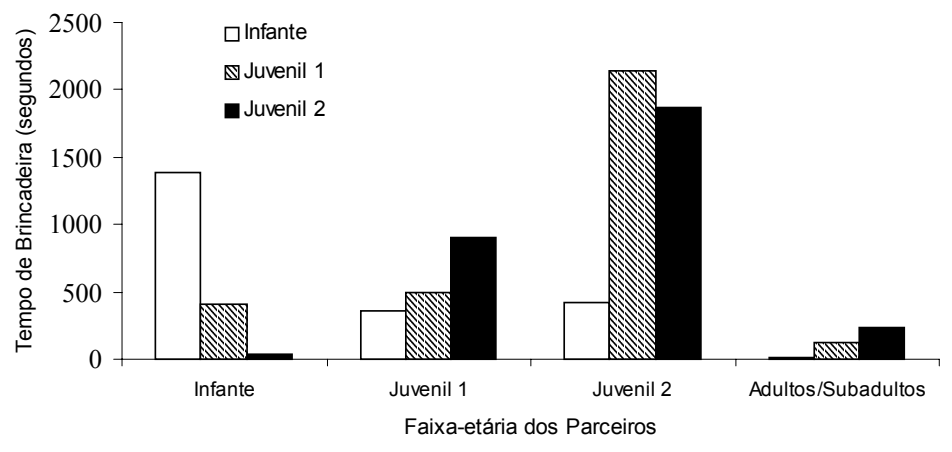

Figura 2. Tempo que os infantes e os juvenis 1 e 2 passam brincando com sujeitos de faixas etárias diferentes.

ra 3). Quanto a estes últimos, o período em questão corresponde à emergência dos comportamentos que classificamos como "quebra inepta" de cocos (ou seja, tratase de uma mudança na natureza da manipulação, e não de uma queda efetiva da atividade manipulatória); esta explicação, entretanto, não se aplica a Joana, a fêmea (a qual, neste período, tendia a permanecer nas proximidades de um irmão recém-nascido, o que pode ter limitado suas possibilidades de exploração de objetos).

A complexidade das formas de manipulação de objetos aumenta com a idade: infantes mais novos manipulam apenas um objeto por vez. Mais tarde, podem manipular ao mesmo tempo dois ou mais objetos, o que é necessário para que haja o desenvolvimento do comportamento de quebra de cocos, cuja ocorrência mais precoce, no presente estudo foi observada em um sujeito com pouco mais de dois anos de idade (mas, ver Ottoni \& Mannu, 2001) (Tabela 2).

\section{Discussão}

Juvenis brincaram mais do que infantes. Pode-se constatar que a mãe não tem um papel relevante na brincadeira social desta espécie, ao contrário do observado, por exemplo, entre fêmeas adultas de macaco resos em situação de liberdade (Fagen, 1981) - as quais brincam com seus filhotes, embora nunca tenham sido vistas brincando com outros adultos (o que também não foi observado entre as fêmeas do presente estudo). Os machos adultos, apesar de também brincarem pouco, foram vis-

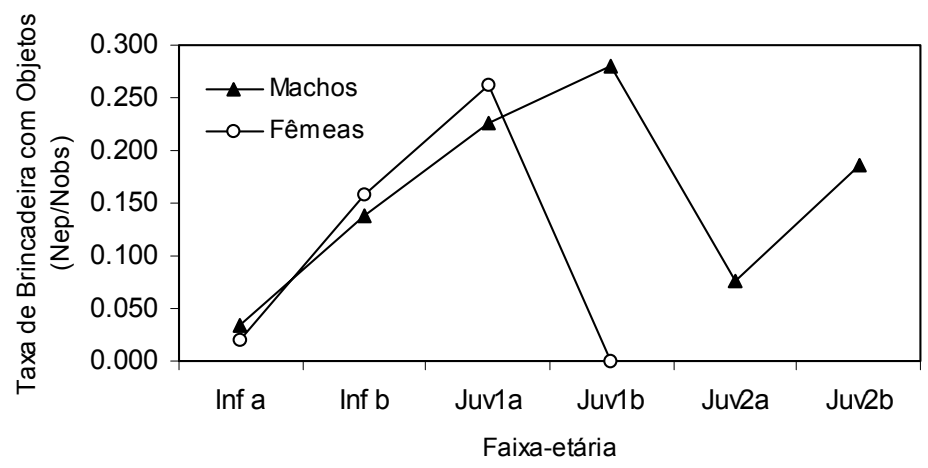

Figura 3. Taxa de brincadeira com objetos (Nep = número de episódios; Nobs $=$ número de observações focais) apresentada pelos sujeitos de $0 \mathrm{a}$ 144 semanas. As categorias infante, juvenil 1 e juvenil 2 foram divididas em infante a ( 0 a 24 semanas), infante b ( 25 a 48 semanas), juvenil 1a (49 a 72 semanas), juvenil $1 \mathrm{~b}$ (73 a 96 semanas), juvenil 2a (97 a 120 semanas) e juvenil $2 b$ (121 a 144 semanas). Os dados referentes a André não foram computados para esta análise, por ter não ter sido possível identificar o sexo. 
Tabela 2. Desenvolvimento da manipulação até o surgimento da quebra de cocos

\begin{tabular}{ll}
\hline Comportamento & Idade (semanas) \\
\hline manipular um objeto ou substrato & 6 a 11 \\
manipular um objeto em relação a substrato & 16 a 27 \\
manipular um objeto em relação a outro & 33 a 49 \\
manipular pelo menos 3 itens & 54 a 111 \\
quebrar coco com sucesso & 106 a $+174^{\mathrm{a}}$ \\
\hline
\end{tabular}

Nota. As idades indicadas correspondem aos sujeitos mais novos e mais velhos que realizaram o comportamento.

${ }^{a}$ Sujeito desaparecido com 174 semanas quando ainda não havia apresentado o comportamento.

tos com mais freqüência envolvidos nas brincadeiras sociais dos infantes e juvenis.

Nos infantes estudados, a exploração de objetos se intensifica com a idade e parece ser importante para o componente individual da aprendizagem da quebra de cocos. A fase de declínio do que denominamos "manipulação exploratória" correspondeu (para 2 entre 3 indivíduos), à fase de emergência das categorias comportamentais associadas à quebra de cocos. Entre os filhotes de chimpanzé do grupo selvagem estudado por Inoue-Nakamura e Matsuzawa (1997), a freqüência de manipulação de pedras e cocos aumenta com a idade, caindo a manipulação isolada de pedras. Com a idade, há um aumento da manipulação simultânea de vários objetos, que envolvem desde rolar uma pedra no chão com uma mão e tocar outra (com a outra mão) até colocar um coco sobre uma pedra e bater contra ele usando outra pedra. Tais ações foram consideradas pelos autores fundamentais para a posterior aprendizagem da quebra.

A ocorrência do comportamento de manipulação de pedras e de "quebra inepta" de cocos, mesmo na ausência de reforço alimentar e a sua intercalação com brincadeira social podem ser indicadores de que estes comportamentos possuem a mesma motivação lúdica, sendo recompensadores per se, assim como a manipulação de pedras por macacos japoneses (Huffman, 1996).

A tolerância em relação aos outros indivíduos do grupo, uma característica acentuada em macacos-prego (Izawa, 1980), é um importante facilitador da aprendizagem social por realce de estímulo (stimulus enhancement): um sujeito que vê outro manipulando pedras e cocos pode se aproximar, observar e também manipular, podendo inclusive ser reforçado pela disponibilidade de restos de endosperma de coco no sítio. O grau de tolerância entre os indivíduos envolvidos, ao influenciar as distâncias interindividuais, estabelece limites para o grau de detalhe em que a observação do comportamento do modelo é possível e, conseqüentemente, quais aspectos do comportamento podem ser efetivamente aprendidos por observação (Coussi-Korbel \& Fragaszy, 1995).

Se a brincadeira social é uma facilitadora da formação de laços entre os membros do grupo, ela pode atuar no sentido de aumentar a tolerância de um sujeito para o outro. Para confirmação desta hipótese, seria necessário estudar grupos com diferentes taxas de brincadeira, além de correlacionar a taxa de brincadeira com a tolerância interindividual nos eventos de observação de quebra. Por outro lado, a observação, por um filhote, de um episódio de quebra proficiente, não garante que o observador necessariamente se interessará em manipular pedras e quebrar cocos, como foi o caso de um dos sujeitos deste estudo: sendo bem tolerado pelo macho dominante, ele ingeria alguns cocos quebrados pelo adulto, sem nunca ter sido observado tentando quebrar cocos por conta própria. Desta forma, a tolerância também pode levar ao parasitismo social, como já foi observado em outros contextos (Ottoni et al., 2001).

Acreditamos que a manipulação exploratória é importante na aprendizagem individual da quebra de cocos e que pode ter sua freqüência aumentada devido à aprendizagem social, que só é possível graças à tolerância entre membros do grupo nesta espécie. Talvez esta elevada tolerância dos macacosprego esteja relacionada à taxa de brincadeira, uma hipótese cuja comprovação depende de futuros estudos comparativos.

\section{Agradecimentos}

Agradecemos ao Parque Ecológico do Tietê, por ternos dado as condições necessárias para a condução da pesquisa; à professora Emma Otta, pela ajuda e pelo interesse e aos pareceristas pelas sugestões. Este trabalho teve o apoio financeiro da FAPESP (processo 99/115732). 


\section{Referências}

Altmann, J. (1974). Observational study of behaviour: Sampling methods. Behaviour, 49, 223-265.

Bateson, P., Mendl, M., \& Feaver, J. (1990). Play in the domestic cat is enhanced by rationing of the mother during lactation. Animal Behaviour, 40, 514-525.

Beckoff, M., \& Allen, C. (1998). Intentional communication and social play: How and why animals negotiate and agree to play. In M. Beckoff \& J. Byers (Orgs.), Animal play: Evolutionary, comparative, and ecological perspectives (pp. 97-114). Cambridge: Cambridge University Press.

Beckoff, M., \& Byers, J. (Orgs.) (1998). Animal play: Evolutionary, comparative, and ecological perspectives. Cambridge: Cambridge University Press.

Biben, M. (1998). Squirrel monkey play fighting: making the case for a cognitive training function for play. In M. Beckoff \& J. Byers (Orgs.), Animal play: Evolutionary, comparative, and ecological perspectives (pp. 161-182). Cambridge:. Cambridge University Press.

Burghart, G. M. (1998). The evolutionary origins of play revisted: Lessons from turtles. In M. Beckoff \& J. Byers (Orgs.), Animal play: Evolutionary, comparative, and ecological perspectives (pp. 1-26). Cambridge: Cambridge University Press.

Chalmers, N. R., \& Locke-Haydon, J. (1984). Correlations among measures of playfulness and skillfulness in captive common marmosets (Callithrix jacchus jacchus). Developmental Psychobiology, 17, 191-208.

Cheney, D. L. (1978). The play partners of immature baboons. Animal Behaviour, 26, 1038-1050.

Coussi-Korbel, S., \& Fragaszy, D. M. (1995). On the relation between social dynamics and social learning. Animal Behaviour, 50, 1441-1553.

Fagen, R. (1981). Animal play behavior. New York: Oxford University Press. Hall, S. (1998). Object play by adult animals. In M. Beckoff \& J. Byers (Orgs.), Animal play: Evolutionary, comparative, and ecological perspectives (pp. 45-58). Cambridge: Cambridge University Press.

Huffman, M. A. (1984). Stone-play of Macaca fuscata in Arashiyama B troop: Transmission of a non-adaptive behavior. Journal of Human Evolution, 13, 725-735.

Huffman, M. A. (1996). Acquisition of innovative cultural behaviors in nonhuman primates: a case study of stone handling, a socially transmitted behavior in Japanese monkeys. In C. M. Heyes \& B. G. Galef (Orgs.), Social Learning in animals: The roots of culture. (pp. 267-289) San Diego: Academic Press.

Inoue-Nakamura, N., \& Matsuzawa, T. (1997) Development of stone tool use by wild chimpanzees (Pan troglodytes). Journal of Comparative Psychology, 111, 159-173.

Izawa, K. (1980). Social behavior of the wild black-capped capuchin (Cebus apella). Primates, 21, 443-467.
Lewis, K. P. (2000). A comparative study of primate play behaviour: implications for the study of cognition. Folia Primatologica, 71, 417-421.

Mendonza-Granados, D., \& Sommer, V. (1995). Play in chimpanzees of Arhem Zoo: Self-serving compromises. Primates, 36, 57-68.

Ottoni, E. B. (2000). EthoLog 2.2: A tool for the transcription and timing of behavior observation sessions. Behavior Research Methods, Instruments, \& Computers, 32, 446-449.

Ottoni, E. B., \& Mannu, M. (2001). Semifree-ranging tufted capuchins (Cebus apella) spontaneously use tools to crack open nuts. International Journal of Primatology, 22, 347-358.

Ottoni, E. B., Resende B. D., Mannu, M., Aquino, C., Sestini, A. E., \& Izar, P. (2001). Tool use, social structure, and information transfer in capuchin monkeys. Advances in Ethology (Supplement to Ethology - Contributions to the XXVII International Ethological Conference), 36, 234.

Pellis, S. M. (1991). How motivationally distinct is play? A preliminary case study. Animal Behaviour, 42, 851-853.

Pereira, M. E., \& Preisser, M. C. (1998). Do strong primate players 'self-handicap' during competitive social play? Folia Primatologica, 69, 177-180.

Perondi, M. A. M., Izar, P., \& Ottoni, E. B. (1995). Uso de ferramentas por macacos-prego (Cebus apella) em condições de semi-cativeiro: observações preliminares. Anais de Etologia, 13, 416.

Rasa, O. A. E. (1984). A motivational analysis of object play in juvenile dwarf mongooses (Helogale undulata rufula). Animal Behaviour, 32, 579-589.

Schiller, P. H. (1978). Innate motor action as a basis of learning: Manipulative patterns in the chimpanzee. In D. Müller-Schwarze (Org.), Evolution of play behavior (pp. 81-92). New York: Academic Press (Texto original publicado em 1949).

Sommer, V., \& Mendonza-Granados, D. (1995). Play as indicator of habitat quality: A field study of langur monkeys (Presbytis entellus). Ethology, 99, 177-192.

Terborgh, J. (1983). Five new world primates. Princeton: Princeton University Press.

Visalberghi, E., Fragaszy, D., \& Savage-Rumbaugh, S. (1995). Performance in a tool using task by common chimpanzees (Pan troglodytes), bonobos (Pan paniscus), an orangutan (Pongo pygmaeus) and capuchin monkeys (Cebus apella). Journal of Comparative Psychology, 109, 52-60.

Walters, J. (1987). Transition to adulthood. In B. B. Smuts, R. M. Seyfarth, R. M. Wrangham \& T. T. Struhsaker (Orgs.), Primate societies (pp.358369). Chicago: University of Chicago Press.

Welker, C., Becker, P., Höhmann, H., \& Schäfer-Witt, C. (1987). Social relations in groups of black-capped capuchin Cebus apella in captivity. Folia Primatologica, 49, 33-37.

Westergaard, G. C., \& Fragaszy, D. M. (1987) The manufacture and use of tools by capuchin monkeys (Cebus apella). Journal of Comparative Psychology, 101, 159-168.

Briseida Dôgo de Resende é doutoranda em Psicologia Experimental, Departamento de Psicologia Experimental, Instituto de Psicologia, Universidade de São Paulo, SP.

Eduardo B. Ottoni, doutor em Psicologia Experimental pela Universidade de São Paulo, é Professor Assistente Doutor do Departamento de Psicologia Experimental do Instituto de Psicologia da Universidade de São Paulo, SP.

Endereço para correspondência: Av. Prof. Mello Moraes, 1721, 05508-900, São Paulo, SP. Telefone: (11)3091.4444 ramal 227. Fax: (11)3091.4357. E-mail: briseida@usp.br 